\title{
Classification and Fascicular Analysis of Variant Branching Pattern of Femoral Nerve for Microsurgical Intervention. A Series of Thirteen Cadavers
}

\author{
Clasificación y Análisis Fascicular de las Variantes en el Patrón de Ramificación del \\ Nervio Femoral en Intervenciones Microquirúrgicas. Una Serie de 13 Cadáveres
}

Rajani Singh* ; Shane Tubbs $^{* *}$ \& Mukesh Singla*

SINGH, R.; TUBBS, S. \& SINGLA, M. Classification and fascicular analysis of variant branching pattern of femoral nerve for microsurgical intervention. A series of thirteen cadavers. Int. J. Morphol., 34(2):561-569, 2016.

SUMMARY: Femoral neuropathy associated with lower limb is treated by surgical intervention through activation/regeneration/ grafting of nerve fibers by a nerve cuff electrode implant or neuro-prosthesis. These procedures require detailed and precise knowledge of neuro-anatomical variants of the femoral nerve and its fascicular anatomy so that the nerve injury can be investigated and treated more efficiently. The aim of the study is to uncover the variations both in the femoral nerve and its branches, to classify them and to bring out corresponding fascicular anatomy using a hypothesis based on the principle of consistency, continuity and traceability of fascicles. The study was carried out in the Department of Anatomy AIIMS Rishikesh using 13 matched lower limbs (26 femoral nerves) from 13 cadavers. The femoral nerve was exposed in the femoral triangle and traced to the posterior abdominal wall. Variations in the shape, size and course of the femoral nerve and its branches were analyzed. The fascicular arrangement was also conceptualized based on the hypothesis. Seven classes, high division, trunk anomaly, semi-scattered, scattered branching pattern, pectocutaneous, lateral cutaneous nerve of thigh and nerve to sartorius anomalies were detected. The corresponding fascicular organizations were modeled. The seven classes along with corresponding fascicular pattern will be very useful for neurosurgeons, radiologists, anesthetists and anatomists in diagnosis and treatment of femoral neuropathy.

KEY WORDS: Variations of femoral branching pattern; Classification of femoral nerve; Fascicular model; Nerve cuff electrode; Femoral neuropathy.

\section{INTRODUCTION}

The femoral nerve is the largest nerve of the lumbar plexus, formed by dorsal divisions of the ventral rami of spinal nerves L2, L3 and L4 and innervates the anterior thigh muscles, hip and knee joints and the skin of the anteromedial thigh (Moore \& Dalley, 1999). It emerges from the lateral border of the psoas major muscle then descends coursing beneath the inguinal ligament. Then it enters the femoral triangle. In the femoral triangle it lays in the groove between the iliacus and psoas major muscles. Further in the thigh, it divides into anterior and posterior divisions near the inguinal ligament (Standring, 2008). The anterior division gives a muscular branch nerve to sartorius which innervates sartorius muscle and two cutaneous branches supplying the anteromedial side of the thigh. The sartorius muscle flexes the leg at the knee joint and rotates it medially. The posterior division gives the cutaneous saphenous nerve and mus- cular branches supplying the vastus medialis, vastus lateralis, vastus intermedius and rectus femoris muscles. The three vasti muscles are important for standing function; they extend the leg at the knee joint without flexing the thigh. The pectineus muscle is innervated by the nerve to pectineus branch of the femoral nerve.

The vastus lateralis and vastus intermedius are commonly targeted for neural prostheses that employ functional electrical stimulation (FES) for standing after spinal cord injury (SCI) (Kobetic et al., 1997; Uhlir et al., 2000; Davis et al., 2001). The vastus medialis is important for locking the knee in terminal extension and preventing patellar drift and lateral subluxation which could be caused by the pull of the vastus lateralis. The biarticulate rectus femoris and sartorius muscles are critically important during

\footnotetext{
* Department of Anatomy, All India Institute of Medical Sciences, Rishikesh, Uttrakhand, India.

** Pediatric Neurosurgery, Children's of Alabama, Birmingham, USA.
} 
the sit-to-stand transition and during stepping and walking (Sharma et al., 1998; Kobetic et al., 1999). They have undesirable actions for standing such as thigh flexion (Uhlir et al.; Triolo et al., 2001).

The variations (in shape, size, course and configuration of branching pattern) will not only confuse the radiologists and thereby neurosurgeons and anesthetists in diagnosis but also mislead them for microsurgical interventions to treat femoral neuropathy. Therefore the classification of these variations will not only facilitate systematic knowledge of the innervation pattern but also its application to systematic diagnosis and treatment of femoral neuropathy. Further the fascicular anatomy will enable the identification of potential therapeutic sites for a nerve cuff electrode implant. Moreover the classification and fascicular configuration will help to locate nerve disposition and identification of nerve injury in imagery and other diagnostic tools. Therefore the aim of the present study is to uncover the classified variant anatomy of the femoral nerve, its branching pattern and fascicular structure based on hypothesis extracted from the conclusions of Gustafson et al. (2009) and their clinical implications.

\section{MATERIAL AND METHOD}

The study was carried out in the Department of Anatomy, AIIMS Rishikesh using 13 matched lower limb pairs, 26 total right and left femoral nerves from 13 (8 male +5 female) cadavers of Indian origin (aged between 70 and 80 years) fixed in $10 \%$ formalin. The femoral triangle was dissected. The femoral nerve was identified and traced upward up to the posterior abdominal wall. Gross variations in the size of the femoral nerve due to its division style, sprouting configuration and anomalous branching pattern were analyzed and classified. Internal variations in fascicular configuration and spatial orientation within the femoral nerve and its branches, based on a hypothesis from the conclusions of Gustafson et al. study coupled with clinical significance, were examined to facilitate a grasp of the clinical implications. The hypothesis is:

Hypothesis. "The fascicular pattern or spatial relationship between fascicles remained consistent, continuous and traceable throughout the compound femoral nerve (CFN) and distal branches represented as individual fascicles/ fascicular bundles in the CFN between the first branching point and the inguinal ligament."

\section{RESULTS}

The variations of branching pattern of CFN observed and were classified as under:

Type-I (High division). In this class of anomaly, the femoral nerve divided dorsally into muscular and ventrally into cutaneous trunks at a point higher than the normal point of division near the inguinal ligament. This reduced the size of CFN and differentiated trunks as described above. The labels

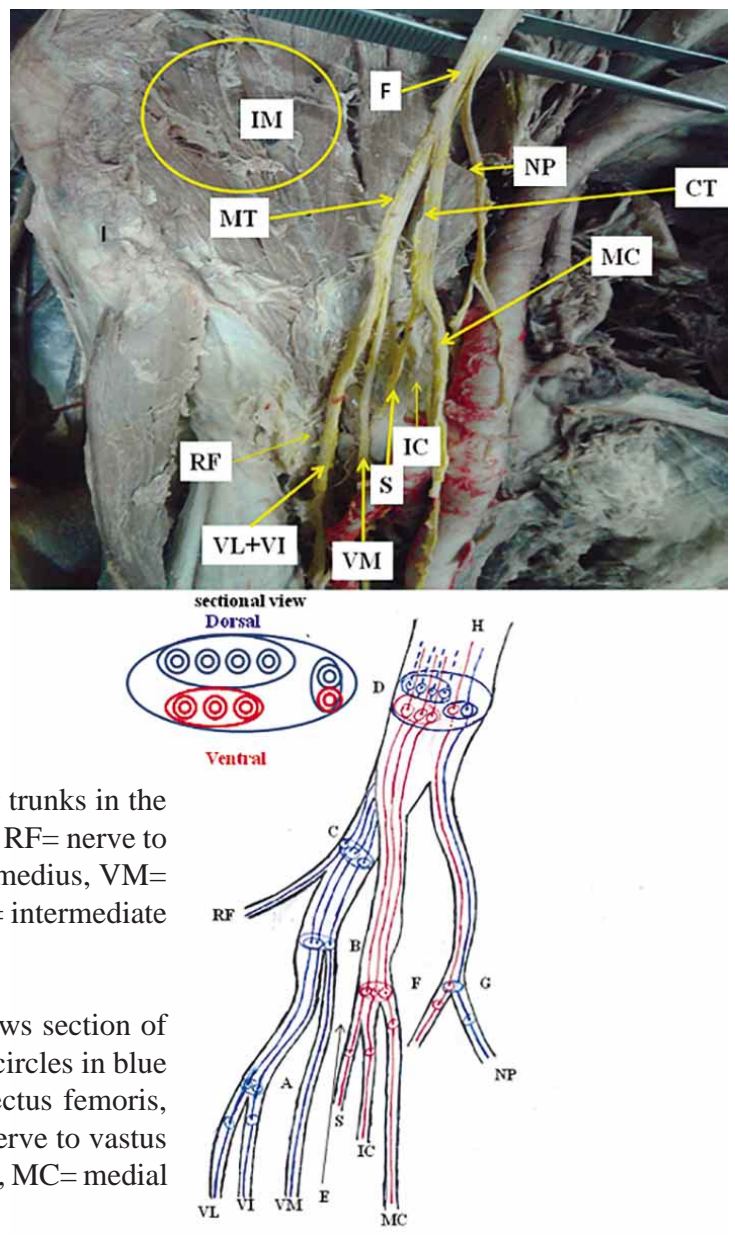

Fig. 1. High division of the femoral nerve into cutaneous and muscular trunks in the iliac fossa. $\mathrm{IM}=$ Iliacus muscle, $\mathrm{F}=$ femoral nerve, $\mathrm{MT}=$ muscular trunk, $\mathrm{RF}=$ nerve to rectus femoris, $\mathrm{VL}=$ nerve to vastus lateralis, $\mathrm{VI}=$ nerve to vastus intermedius, $\mathrm{VM}=$ nerve to vastus medialis, $\mathrm{CT}=$ cutaneous trunk, $\mathrm{S}=$ saphenous nerve, $\mathrm{IC}=$ intermediate cutaneous nerve of thigh and $\mathrm{MC}=$ medial cutaneous nerve of thigh.

Fig. 1. A) Fascicular presentation in Type-I and II. Sectional view shows section of femoral nerve at $\mathrm{D}$; circles in red are fascicles of cutaneous nerves and circles in blue are fascicles of motor branches of the femoral nerve. $\mathrm{RF}=$ nerve to rectus femoris, $\mathrm{VL}=$ nerve to vastus lateralis, $\mathrm{VI}=$ nerve to vastus intermedius, $\mathrm{VM}=$ nerve to vastus medialis, $\mathrm{S}=$ saphenous nerve, $\mathrm{IC}=$ intermediate cutaneous nerve of thigh, $\mathrm{MC}=$ media cutaneous nerve of thigh and $\mathrm{NP}=$ nerve to pectineus. 
'muscular' and 'cutaneous' trunks have been used because exclusively, all the muscular/motor branches and all the cutaneous /sensory branches emanated from the muscular trunk and cutaneous trunk respectively. The sequence of nerves emerging from the muscular trunk was rectus femoris (RF), vastus lateralis (VL), vastus intermedius (VI) and vastus medialis (VM) from lateral to medial side entering the dorsal aspect. The cutaneous trunk separated into the saphenous nerve $(\mathrm{S})$, the intermediate cutaneous (IC) and medial cutaneous (MC) nerves of the thigh sequentially from the lateral to the medial side, entering the ventral aspect. This anomalous division was observed in femoral nerves on to the right side in specimens 7 and 3 , at $2.5 \mathrm{~cm}$ and $5.5 \mathrm{~cm}$ above the midpoint of the inguinal ligament, respectively (Fig.1).

Type-II (Trunk anomaly). In this class of anomaly, the femoral nerve bifurcated into muscular trunk dorsally and cutaneous trunk ventrally near the inguinal ligament and subdivided further into the nerve to the quadriceps femoris and the cutaneous branches/nerves. The sequence of nerves was same as described in type-I. This pattern was observed bilaterally in the 2 nd, 3 rd and 7 th specimens on the right and in the 4th on the left femoral nerves (Fig.1), as depicted in the Table I.

Type-III (semi-scattered branching anomaly). In this category, the femoral nerve split directly into a muscular trunk laterally and scattered cutaneous branches medially. The muscular trunk divided into a nerve to the quadriceps femoris in the same sequence as in Type-I and Type-II. Thesequence of cutaneous nerves emanating directly from the femoral nerve also remained same as from cutaneous trunk in type-I and Type-II. This type of configuration was observed bilaterally in specimens $1,5,6,9,10,12$ and 13 and in specimens 3 and 4 on the left and right sides respectively (Fig. 2).
Type-IV (scattered branching anomaly). In this type, all muscular and cutaneous branches sprouted directly from the compound femoral nerve (CFN) but in the iliac fossa. But the spatial sequence of these branches remained the same as described above. This type of arrangement was observed in specimen 11 bilaterally (Fig. 3).

The configurations of branches and size of femoral nerve in Type-II to Type-IV are new and different from the classical anterior and posterior divisions.

Type-Va (pectocutaneous anomaly). Pectocutaneous new nerve branched off from CFN anomalously from a point lying much higher than the normal origin. This nerve bifurcates into the cutaneous nerve and the nerve to the pectineus near the inguinal ligament. It has been named as the pectocutaneous nerve (Fig. 4). In this type of branching pattern, this nerve arose at 7 , 7.5 and $9 \mathrm{~cm}$ above the midpoint of inguinal ligament in 3 specimen viz. 3rd (right side), 9th (right side) and 10th (left side).

Type-Vb. In specimen 12 (right side) the lateral cutaneous nerve of the thigh arose from L2 together with the pectocutaneous nerve (Fig. 5).

TypeVI (lateral cutaneous nerve of thigh anomaly). The lateral cutaneous nerve of thigh normally arises from the lumbar plexus, but in this class, it emerged directly from the CFN in specimen 8 on the right side (Fig. 6).

Type-VII (nerve to sartorius anomaly). In this category, the nerve to sartorius arose from the main trunk of the femoral nerve on the lateral aspect in place of the medial aspect of the anterior division in specimens 4 and 6 bilaterally and specimen 1 on right side (Fig. 2).

These variations of the $\mathrm{CFN}$ and its branching pattern are summarized in Table I. Occasionally, there was more than

Table I. Anomalies associated with branching pattern of femoral nerve.

\begin{tabular}{llllc}
\hline S. No. & Class & Anomaly & Specimen no./side & n \\
\hline 1 & Type-I & High division & 3 (right) and 7 (right) & 2 \\
2 & Type-II & Trunk & 2 (1 bilaterally) & 2 \\
& & & 3 (right), 4 (left) and 7(right) & 3 \\
3 & Type-III & Semiscattered branching & $1,5,6,9,10,12,13$ (7 bilaterally) & 14 \\
& & & 3 (left) and 4 (right) & 2 \\
4 & Type-IV & Scattered branching & 11 (1 bilaterally) & 2 \\
5 & Type-Va & Pectocutaneous anomaly & 3 (right), 9 (right) and 10 (left) & 3 \\
6 & Type-Vb & Pectocutaneous from L2 & 12 (right) & 1 \\
7 & Type-VI & Lateral cutaneous nerve of thigh & 12 (right) and 8 (right) & 2 \\
8 & Type-VII & Nerve to Sartorius & 4 and 6 (2 bilaterally) & 4 \\
& & & 1 (right) & 1 \\
\hline
\end{tabular}



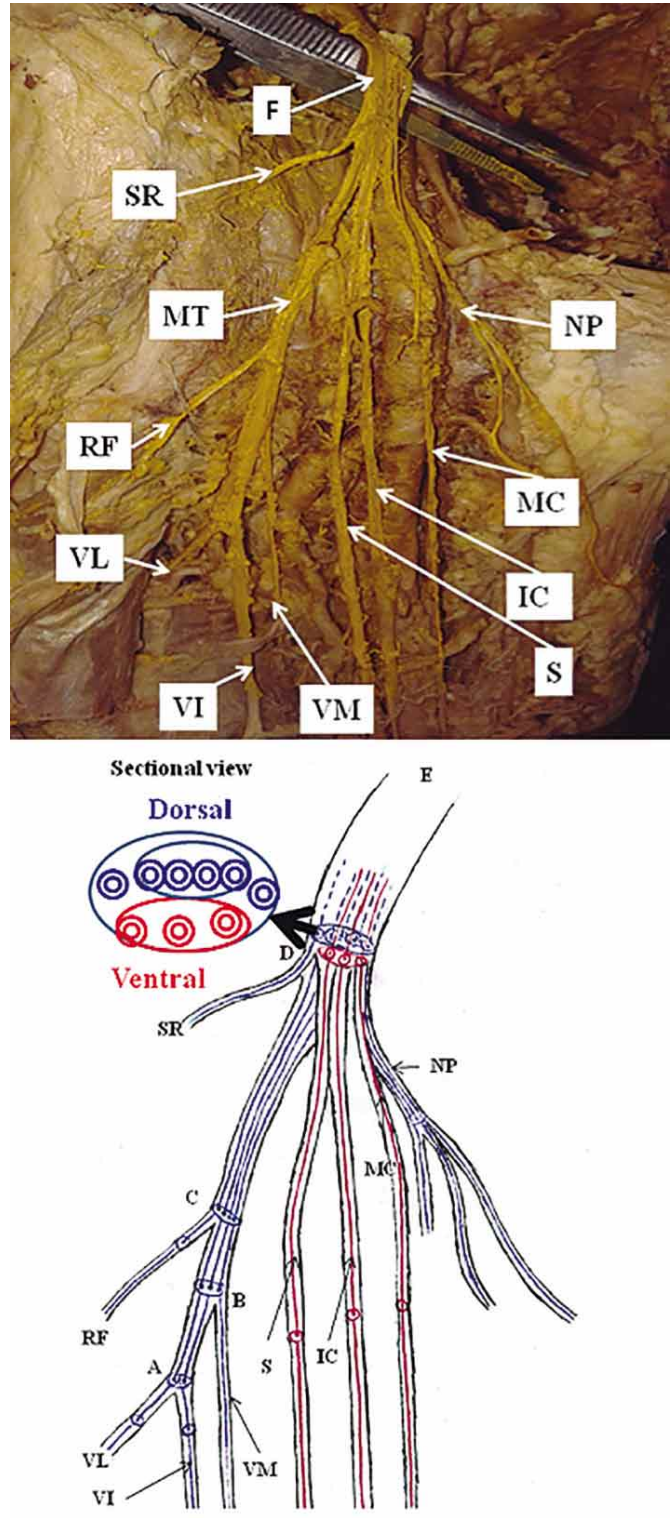

Fig. 2. Cutaneous branches arising from femoral nerve and all muscular branches from muscular trunk. $\mathrm{F}=$ femoral nerve, $\mathrm{SR}=$ nerve to sartorius, $\mathrm{MT}=$ muscular trunk, $\mathrm{RF}=$ nerve to rectus femoris, $\mathrm{VL}=$ nerve to vastus lateralis, $\mathrm{VI}=$ nerve to vastus intermedius, $\mathrm{VM}=$ nerve to vastus medialis, $\mathrm{S}=$ saphenous nerve, $\mathrm{IC}=$ intermediate cutaneous nerve of thigh, $\mathrm{MC}=$ medial cutaneous nerve of thigh and $\mathrm{NP}=$ nerve to pectineus.

Fig. 2. A) Fascicular anatomy in Type-III. Sectional view shows section of femoral nerve at $\mathrm{D}$; circles in red are fascicles of cutaneous nerves and circles in blue are fascicles of motor branches of femoral nerve. $\mathrm{SR}=$ nerve to sartorius, $\mathrm{RF}=$ nerve to rectus femoris, $\mathrm{VL}=$ nerve to vastus lateralis, $\mathrm{VI}=$ nerve to vastus intermedius, $\mathrm{VM}=$ nerve to vastus medialis, $\mathrm{S}=$ saphenous nerve, $\mathrm{IC}=$ intermediate cutaneous nerve of thigh, $\mathrm{MC}=$ medial cutaneous nerve of thigh nd $\mathrm{NP}=$ nerve to pectineus.

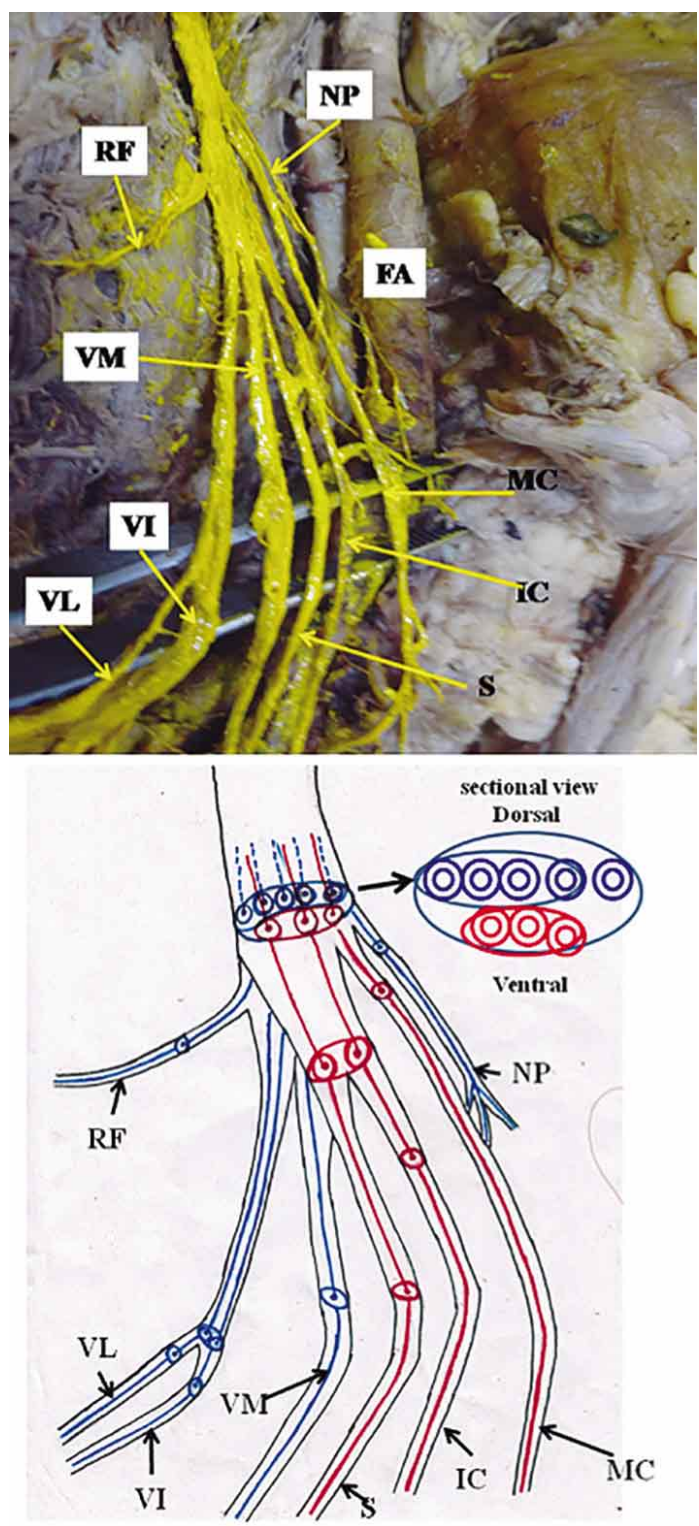

Fig. 3. All branches arise from femoral nerve directly without bifurcating into anterior and posterior divisions in iliac fossa. $\mathrm{F}=$ femoral nerve, $\mathrm{FA}=$ femoral artery, $\mathrm{VL}=$ nerve to vastus lateralis, $\mathrm{VI}=$ nerve to vastus intermedius, $\mathrm{VM}=$ nerve to vastus medialis, $\mathrm{S}=$ saphenous nerve, $\mathrm{IC}=$ intermediate cutaneous nerve of thigh and $\mathrm{MC}=$ medial cutaneous nerve of thigh.

Fig. 3. A) Fascicular anatomy in type-IV. Sectional view shows section of femoral nerve; circles in red are fascicles of cutaneous nerves and circles in blue are fascicles of motor branches of femoral nerve. $\mathrm{RF}=$ nerve to rectus femoris, $\mathrm{VL}=$ nerve to vastus lateralis, $\mathrm{VI}=$ nerve to vastus intermedius, $\mathrm{VM}=$ nerve to vastus medialis, $\mathrm{S}=$ saphenous nerve, $\mathrm{IC}=$ intermediate cutaneous nerve of thigh, $\mathrm{MC}=$ medial cutaneous nerve of thigh, $\mathrm{NP}=$ nerve to pectineus and $\mathrm{IG}=$ inguinal ligament. 


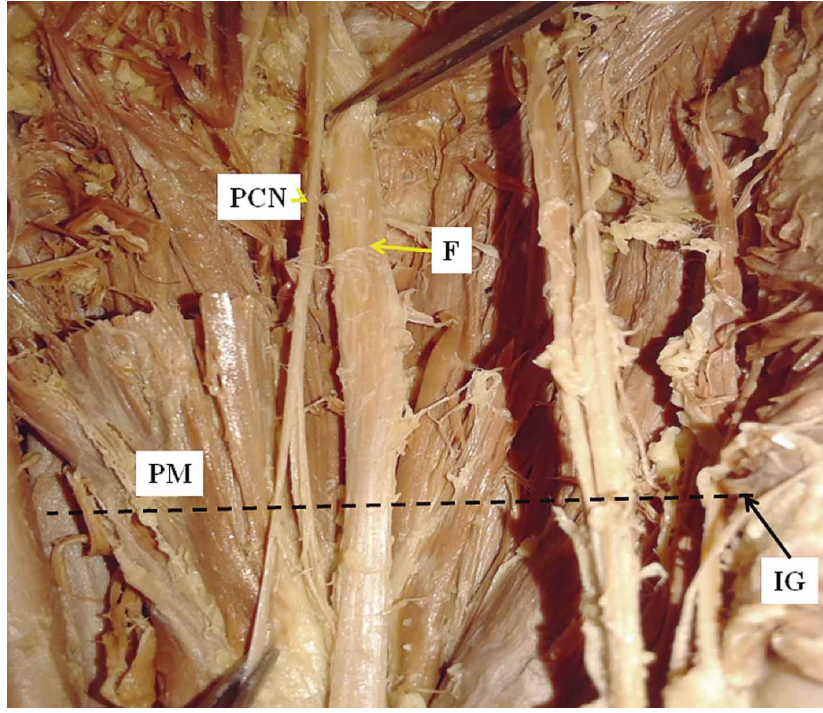

Fig. 4. Nerve to pectineous from femoral nerve high in iliac fossa above the midpoint of the inguinal ligament. $\mathrm{F}=$ femoral nerve, $\mathrm{PCN}=$ pectocutaneous, $\mathrm{PM}=$ psoas major muscle and $\mathrm{IG}=$ inguinal ligament.

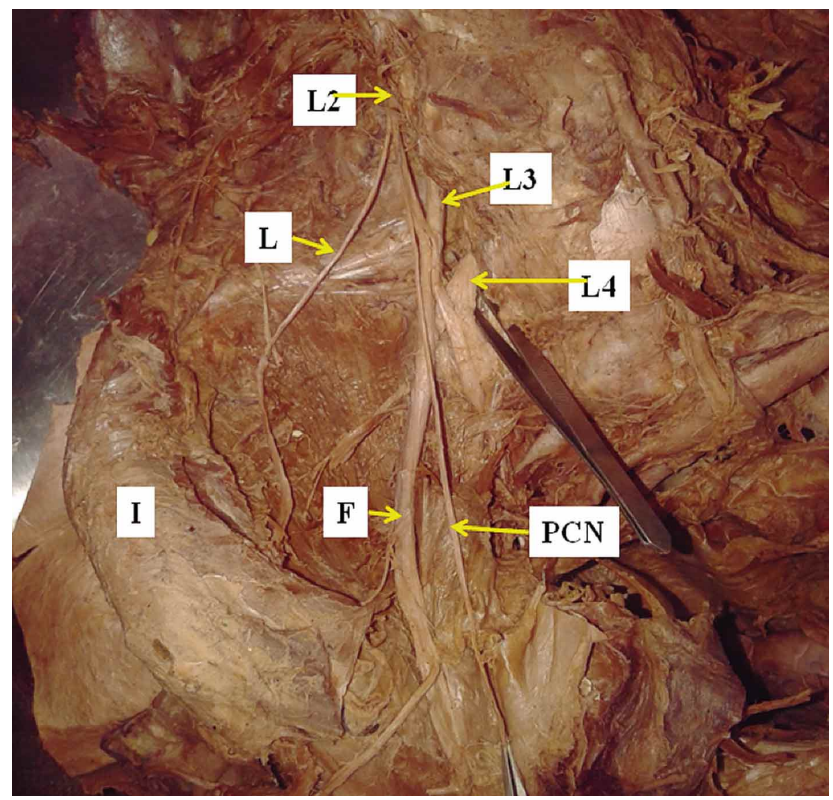

Fig. 5. Pectocutaneous nerve in common with lateral cutaneous nerve of thigh from L2; L2, L3 and L4 are lumbar spinal nerves. $\mathrm{F}=$ femoral nerve, $\mathrm{PCN}=$ pectocutaneous nerve, $\mathrm{L}=$ lateral cutaneous nerve of thigh, $\mathrm{I}=$ iliac crest and $\mathrm{IG}=$ inguinal ligament.

one anomaly in the same femoral nerve. Some variations as described here have not previously been reported so far, but they have clinical implications.

The fascicular configuration model of Type-I, II, III and IV of CFN and distal branches was brought out in Figures 1A, 2A and 3A based on the hypothesis from Gustafson's study. In rest of categories, Type $\mathrm{Va}, \mathrm{Vb}, \mathrm{VI}$, and VII fascicular arrangement was predicted in the discussion section.

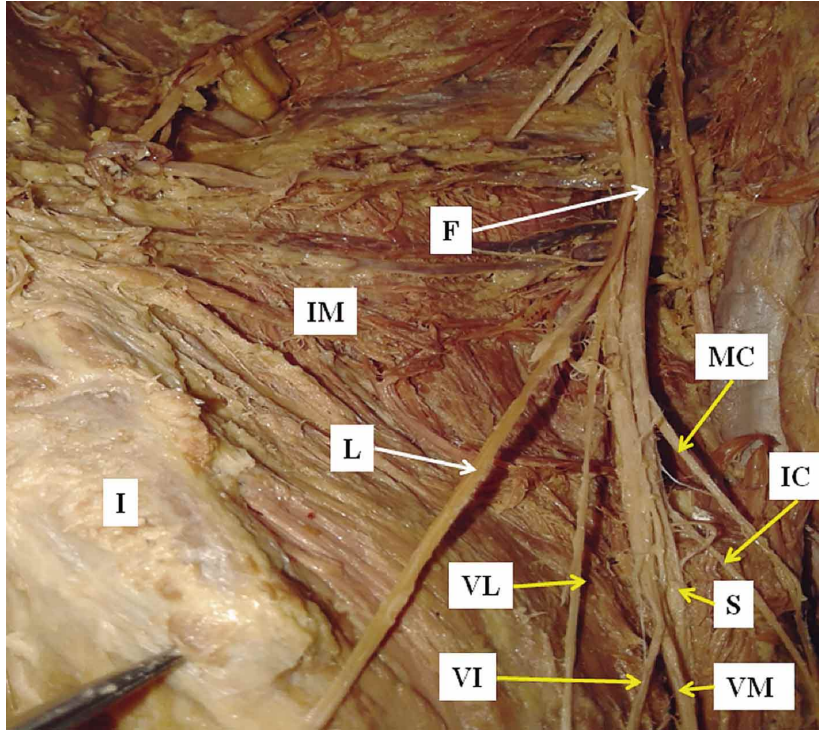

Fig. 6. Lateral cutaneous nerve of thigh from femoral nerve. $\mathrm{IG}=$ inguinal ligament, $\mathrm{F}=$ femoral nerve, $\mathrm{IM}=$ iliacus muscle, $\mathrm{I}=$ iliac crest, $\mathrm{L}=$ lateral cutaneous nerve of thigh, $\mathrm{VL}=$ nerve to vastus lateralis, $\mathrm{VI}=$ nerve to vastus intermedius, $\mathrm{VM}=$ nerve to vastus medialis, $\mathrm{S}=$ saphenous nerve, $\mathrm{IC}=$ intermediate cutaneous nerve of thigh and $\mathrm{MC}=$ medial cutaneous nerve of thigh.

\section{DISCUSSION}

The variations in configuration and branching pattern, shape and size of the CFN were observed and classified in this study of 26 specimens of femoral nerves from 13 cadavers. In Type-I consisting of high branching point anomaly, the size of the compound femoral nerve was drastically reduced and the branching pattern was modified. In place of the bifurcation into anterior and posterior divisions containing a mixed pattern of cutaneous and muscular branches, as described in Gray's Anatomy (Stranding), the femoral nerve divided into muscular (motor) and cutaneous (sensory) trunks in present study. This configuration or arrangement of sensory and motor fibers into separate bundles in corresponding trunks at the division point is anomalous and unusual. Saha \& Pakhiddey (2013) observed the femoral nerve forming two divisions $4.1 \mathrm{~cm}$ above the inguinal ligament. In two lumbar plexuses, the femoral nerve divided into anterior and posterior divisions above the inguinal ligament at $4 \mathrm{~cm}$ in one right and $3.8 \mathrm{~cm}$ in another left limb (Astik \& Dave, 2011). Das \& Vasudeva (2007) observed the femoral nerve dividing $3.2 \mathrm{~cm}$ above the inguinal ligament bilaterally in a male cadaver. But in the present study, the femoral nerve bifurcated above the inguinal ligament at $2.5 \mathrm{~cm}$ in one of the left and $5.5 \mathrm{~cm}$ in another limb (Fig. 1). 
The sequence of the cutaneous (sensory) and muscular (motor) nerves, having emerged from the cutaneous and muscular trunks in Type-II anomaly, remained consistent with Type-I except the short CFN due to high origin of trunks (Fig. 1) but different from normal femoral nerve. In Type-III (Fig. 2), the cutaneous branches emanated directly from medial side and the muscular trunk from the lateral side of CFN whereas in type -IV, all the cutaneous and muscular branches sprouted directly from the main femoral nerve but in the iliac fossa (Fig. 3). TypeII, Type-III and Type-IV anomalies are new findings and reported for the first time.

Gustafson et al. always found the major branches involved in standing (vastus medialis, vastus intermedius, and vastus lateralis nerves) were centrally located, while the sensory branches and the branches not implicated in standing (saphenous, medial cutaneous, sartorius, and rectus femoris nerves) were located in the medial or lateral part. Such branching pattern of the femoral nerve is similar to the present study. Aizawa (1992) reported that the medial cutaneous nerve branches and the vastus medialis, vastus intermedius, vastus lateralis, and rectus femoris nerves were arranged medially to laterally. This pattern is consistent with the present study with the exception that the intermediate cutaneous nerve of the thigh and the saphenous nerve lay between the medial cutaneous nerve of the thigh and the nerve to the vastus medialis, whereas Gustafson et al. did not mention the intermediate cutaneous nerve of the thigh.

In Type-Va, pectocutaneous anomaly, Astik \& Dave (2011) observed a high origin of the nerve to the pectineous at $4.5 \mathrm{~cm}$ above the inguinal ligament bilaterally, and in another case the same nerve emanated from the anterior division at $2.5 \mathrm{~cm}$ above the inguinal ligament unilaterally. Paterson (1891) and Macalister (1889) also observed the nerve to the pectineus arising from the femoral nerve in the abdomen along with high origin of the medial cutaneous nerve of the thigh. In our study, a high origin of the nerve to the pectineus in the iliac fossa was observed in three femoral nerves at distances of 7, 7.5 and $9 \mathrm{~cm}$ above the inguinal ligament unilaterally. These are altogether different locations of the origin of the nerve to the pectineus from those reported in the above studies. In Type $\mathrm{Vb}$, the pectocutaneous nerve arose from L2 together with the lateral cutaneous nerve of the thigh. This variation is not reported in literature so far.

In Type-VI (Lateral cutaneous nerve of thigh anomaly), Astik \& Dave observed this abnormality in four plexuses. The lateral cutaneous nerve of the thigh arose directly from the femoral nerve in six $(10 \%)$ plexuses (Sim
\& Webb, 2004). Dias Filho et al. (2003) reported the origin of the lateral cutaneous nerve of the thigh from the femoral nerve inferior to the inguinal ligament in one case. Uzmansel et al. (2006) reported the origin of the accessory lateral cutaneous nerve of the thigh from the femoral nerve above the inguinal ligament. In present study, in one of the plexuses, the lateral cutaneous nerve of the thigh arose from the femoral nerve. Type VII (Nerve to sartorius anomaly), the nerve to the sartorius arose from the lateral aspect in five femoral nerves in the present study in place of arising from the anterior division on the medial aspect of the femoral nerve. Gustafson et al. also observed this pattern in two specimens.

Fascicular anatomy. It is essential to comprehend the fascicular organization and its configuration inside the nerves, not only to analyze the signs and symptoms to examine the root cause of the disease, but also to evolve computer models for the design and development of suitable nerve cuff electrodes and their implantation at potential therapeutic sites for activation or stimulation in the treatment of neuropathy. Accurate and targeted nerve block is possible through precise knowledge of fascicular anatomy. The modifications in the organization of the fascicular pattern due to the classified variations can be analyzed as under. The hypothesis associated with concept of wire like structure of fascicle makes the fascicular model very simplistic. So in the 'high division' case (Type-I), the schematic fascicular diagram (Fig. 1A) presents the configuration of the fascicles in CFN and its branching pattern. The sensory fascicles are shown in red and motor fascicles in blue color in the diagram. Major variations in the fascicular arrangement in this class are short extension of fascicle in CFN owing to high division. In the Type-II class of trunk anomaly, the muscular trunk consists of groups of fascicles corresponding to nerve to sartorius, and nerve to quadriceps femoris supplying these muscles and cutaneous trunk contains all bundles of cutaneous fascicles innervating front of the thigh; the pattern is shown in Figure 1A. As regards the Type-III semi-scattered anomaly, the muscular trunk possesses bundle of fascicles pertaining to nerves to sartorius and to quadriceps. The groups of sensory fascicles continue directly from CFN to cutaneous branches as depicted in Figure 2A. But in Type-IV scattered branches anomaly, the bundles of fascicles directly emanate from CFN and regrouping into all the muscular and cutaneous branches separately (Fig. 3A). These Type-III and Type-IV anomalies depict a different from normal fascicular arrangement. The motor fascicular groups will occupy the posterolateral spatial position, maintaining consistency from the proximal compound femoral nerve through the muscular trunk up to the distal branches and the sensory fascicular bundles will occupy the anteromedial 
space in the femoral nerve to maintain consistency and traceability.

In Type-Va, the mixed fascicles of pectocutaneous nerve will lie in the anteromedial part of the CFN above the point of origin and the same will remain absent from $\mathrm{CFN}$ in the lower part due to its high origin. In Type- $\mathrm{Vb}$, the pectocutaneous nerve arises from L2 together with the lateral cutaneous nerve of the thigh. The fascicle for this nerve will remain absent from the CFN. In Type-VI, as the lateral cutaneous nerve of the thigh arises from the femoral nerve in place of the lumbar plexus, the compound femoral nerve will contain additional fascicle corresponding to this nerve in the lateral side. In Type-VII (Nerve to sartorius anomaly), the motor fascicles of the nerve to the sartorius will occupy the lateral most quadrant of the compound femoral nerve, whereas normally these are expected in the medial side.

As per hypothesis and electrical conductor model the arrangement of fascicular bundles/fascicles will be controlled by sequence of femoral branches. Classification will help in locating specific fascicles

Clinical significance. It is estimated that about $5 \%$ of the population has some form of neuropathy, and there is up to a $5 \%$ incidence of peripheral nerve injuries (Martyn \& Hughes, 1997; England \& Asbury, 2004). The femoral nerve, the psoas major and iliacus muscles are covered by the iliacus fascia forming a tight fascial compartment. So the formation of an iliacus hematoma in this area causes a femoral nerve lesion or compression in cases of femoral nerve palsy or neuropathy after anticoagulant treatment (Galzio et al., 1983) or vessel catheterization (Warfel et al., 1993); the existence of some variant muscles or variations in branching pattern of the femoral nerve can increase more chances of nerve lesions or compressions.

The femoral neuropathy/injury can also occur secondary to direct trauma, stretch injury, ischemia, invasion by external/internal pathogens, toxins, drugs, environmental hazards, misuse of limbs, congenital anomalies. Grossly, a nerve injury/lesion disrupts the fascicles/nerve fibers partially/fully causing femoral dysfunction/impairment of lower limb functions creating diseases pertaining to various degrees of paralysis etc. The diagnosis of these diseases require identification and localization of partial/full neural injury to the specific fascicles/groups of fascicle or nerve and treatment by regeneration/stimulation/grafting and proper insertion of a nerve cuff electrode at safe and potential neuro-therapeutic sites of nerve/nerve fibers of femoral nerve and its branches responsible for standing, walking and other impaired functions of the lower limb.
The identification and localization of site of injury in fascicles/nerves is done by FES, precise imaging by advanced magnetic resonance neurography imaging system (Chhabra et al., 2013) and modern imaging techniques with high resolution or $3 \mathrm{D}$ colored sonography. Improvement in accurate interpretation of these tools can be done by knowing the classified femoral nerve variations and fascicular organization models described in fascicular anatomy section. Actual identification of site of nerve injury in corresponding nerve/fascicle would improve neuroprosthetic performance by extending standing time and eliminating the need for multiple implants (Grill \& Mortimer, 1996; Choi et al., 2001; Tyler \& Durand, 2002). Internal and external morphology of nerve provide important design parameters for constructing nerve cuff electrodes to avoid mechanical trauma, maximize stimulation efficiency and develop implementation strategies for advanced neural prostheses (Naples et al., 1990; Grill \& Mortimer, 2000).

Femoral nerve block is performed on the main trunk of the femoral nerve just below the inguinal ligament (Ellis et al., 2004). The nerve block in case of a higher division of the femoral nerve in the iliac fossa will be incomplete because a division rather than entire femoral nerve might be blocked. Thus, variant origins of the femoral nerve and its branches have wide clinical relevance for both imagery interpretation and nerve blocking in neurosurgical intervention. The origin of the lateral cutaneous nerve of the thigh from the femoral nerve can affect the clinical efficacy of lumbar plexus blockade, since femoral nerve blockade in such cases is likely to produce an undesirable blockade in the area of distribution of the lateral cutaneous nerve of the thigh (Sharrock, 1980). Knowledge of variations in the origin of the lateral cutaneous nerve of the thigh from the femoral nerve is useful for clinicians who are treating patients with meralgia paresthetica (Astik \& Dave, 2011), and for anesthetists giving targeted blocks in the femoral or lateral cutaneous nerve of the thigh.

\section{CONCLUSION}

Classification of variations of femoral nerve and its branching pattern coupled with fascicular model will help, besides systematizing anatomical knowledge, in analyzing and treating femoral neuropathy. Systematic knowledge of the classified anatomical variations of the femoral nerve is essential for neurosurgeons to avoid iatrogenic injury to the femoral nerve and its branches or related fascicles. The effect of these variations on blockade of the femoral and lateral cutaneous nerve of the thigh is yet to be investigated 
clinically in detail. Variant origins of the nerve to the pectineus in the abdomen are morphologically important for anatomists. The study is very crucial to imagery interpretation.

\section{ACKNOWLEDGEMENTS}

Authors are thankful to Head of Institute for permitting the work to be carried out in the Department of Anatomy. Authors are also thankful to the families who donated the bodies of their kith and kins for research. Last but not the least, authors are indebted to Mr. Man Singh father of Dr. Rajani Singh for critically reading the manuscript. Nevertheless, authors acknowledge the staff associated to dissection hall for their assistance. There is no conflict of interest. No funding has been received from any institute in regards with the article.

SINGH, R.; TUBBS, S. \& SINGLA, M. Clasificación y análisis fascicular de las variantes en el patrón de ramificación del nervio femoral en intervenciones microquirúrgicas. Una serie de 13 cadáveres. Int. J. Morphol., 34(2):561-569, 2016.

RESUMEN: La neuropatía femoral asociada con el miembro inferior es tratada por intervención quirúrgica a través de activación, regeneración e injerto de fibras nerviosas mediante un implante de electrodo de manguito de nervios o neuro-prótesis. Estos procedimientos requieren un conocimiento detallado y preciso de las variantes neuro-anatómicas del nervio femoral y su anatomía fascicular de modo que la lesión del nervio pueda ser investigada y tratada de manera más eficiente. El objetivo del estudio fue descubrir las variaciones tanto en el nervio femoral y sus ramas y clasificarlos a partir de la anatomía fascicular utilizando una hipótesis basada en el principio de la continuidad y trazabilidad de los fascículos correspondientes. El estudio se llevó a cabo en el Departamento de Anatomía AIIMS Rishikesh utilizando 13 miembros inferiores pareados (26 nervios femorales) de 13 cadáveres. El nervio femoral se expuso en el triángulo femoral y fue trazado en la pared abdominal posterior. Se analizaron las variaciones en la forma, tamaño y trayecto del nervio femoral y sus ramas. El patrón fascicular fue conceptulizado de acuerdo a la hipótesis planteada. Se detectaron anomalías clasificadas en: siete clases, división alta, anomalías de tronco, semi-dispersos, patrón de ramificación dispersa, pectocutáneo, nervio cutáneo lateral y nervio del músculo sartorio. Las clasificaciones junto con el patrón fascicular correspondientes serán de gran utilidad para los neurocirujanos, radiólogos, anestesistas y anatomistas en el diagnóstico y tratamiento de la neuropatía femoral.

PALABRAS CLAVE: Variaciones de los patrones de ramos femorales; Clasificación del nervio femoral; Modelo fascicular; Manguito-electrodo del nervio.

\section{REFERENCES}

Aizawa, Y. On the organization of the Plexus lumbalis. I. On the recognition of the three-layered divisions and the systematic description of the branches of the human femoral nerve. Okajimas Folia Anat. Jpn., 69(1):35-74, 1992.

Astik, R. B. \& Dave, U. H. Anatomical variations in formation and branching pattern of the femoral nerve in iliac fossa: A study in 64 human lumbar plexuses. People's J. Sci. Res., 4(2):14-9, 2011.

Chhabra, A.; Zhao, L.; Carrino, J. A.; Trueblood, E.; Koceski, S.; Shteriev, F.; Lenkinski, L.; Sinclair, C. D. J. \& Andreisek, G. MR Neurography: Advances. Radiol. Res. Pract., 2013:809568, 2013.

Choi, A. Q.; Cavanaugh, J. K. \& Durand, D. M. Selectivity of multiple-contact nerve cuff electrodes: a simulation analysis. IEEE Trans. Biomed. Eng., 48(2):165-72, 2001.

Das, S. \& Vasudeva, N. Anomalous higher branching pattern of the femoral nerve: a case report with clinical implications. Acta Medica (Hradec Kralove), 50(4):245-6, 2007.

Davis, J. A. Jr.; Triolo, R. J.; Uhlir, J. P.; Bhadra, N.; Lissy, D. A.; Nandurkar, S. \& Marsolais, E. B. Surgical technique for installing an eight-channel neuroprosthesis for standing. Clin. Orthop. Relat. Res., (385):237-52, 2001.

Dias Filho, L. C.; Valença, M. M.; Guimarães Filho, F. A.; Medeiros, R. C.; Silva, R. A.; Morais, M. G.; Valente, F. P. \& França, S. M. Lateral femoral cutaneous neuralgia: an anatomical insight. Clin. Anat., 16(4):309-16, 2003.

Ellis, H.; Feldman, S. A. \& Harrop-Griffiths, W. Anatomy for Anaesthetists. $8^{\text {th }}$ ed. Malden, (Mass)., Blackwell Pub., 2004. pp.188-91.

England, J. D. \& Asbury, A. K. Peripheral neuropathy. Lancet, 363(9427):2151-61, 2004.

Galzio, R.; Lucantoni, D.; Zenobii, M.; Cristuib-Grizzi, L.; Gadaleta, A. \& Caffagni, E. Femoral neuropathy caused by iliacus hematoma. Surg. Neurol., 20(3):254-7, 1983.

Grill, W. M. Jr. \& Mortimer, J. T. Quantification of recruitment properties of multiple contact cuff electrodes. I. E. E. E. Trans. Rehabil. Eng., 4(2):49-62, 1996.

Grill, W. M. \& Mortimer, J. T. Neural and connective tissue response to long-term implantation of multiple contact nerve cuff electrodes. J. Biomed. Mater. Res., 50(2):215-26, 2000.

Gustafson, K. J.; Pinault, G. C.; Neville, J. J.; Syed, I.; Davis, J. A. Jr.; Jean-Claude, J. \& Triolo, R. J. Fascicular anatomy of human femoral nerve: implications for neural prostheses using nerve cuff electrodes. J. Rehabil. Res. Dev., 46(7):973-84, 2009. 
SINGH, R.; TUBBS, S. \& SINGLA, M. Classification and fascicular analysis of variant branching pattern of femoral nerve for microsurgical intervention. A series of thirteen cadavers. Int. J. Morphol., 34(2):561-569, 2016.

Kobetic, R.; Triolo, R. J. \& Marsolais, E. B. Muscle selection and walking performance of multichannel FES systems for ambulation in paraplegia. IEEE Trans. Rehabil. Eng., 5(1):239, 1997.

Kobetic, R.; Triolo, R. J.; Uhlir, J. P.; Bieri, C.; Wibowo, M.; Polando, G.; Marsolais, E. B.; Davis, J. A. Jr. \& Ferguson, K. A. Implanted functional electrical stimulation system for mobility in paraplegia: a follow-up case report. IEEE Trans. Rehabil. Eng., 7(4):390-8, 1999.

Macalister, A. A Text-Book of Human Anatomy. London, Griffin, 1889. pp.467-90.

Martyn, C. N. \& Hughes, R. A. Epidemiology of peripheral neuropathy. J. Neurol. Neurosurg. Psychiatry, 62(4):310-8, 1997.

Moore, K. L. \& Dalley, A. F. Clinically Oriented Anatomy. 4th ed. Philadelphia, Lippincott Williams \& Wilkins, 1999.

Naples, G. G.; Mortimer, J. T. \& Yuen, G. H. Overview of Peripheral Nerve Electrode Design and Implantation. In: Agnew, W. F. \& McCreery, D. B. (Eds.). Neural Prostheses: Fundamental Studies. Englewood Cliffs (N. J.), Prentice Hall, 1990. pp.10744.

Paterson, A. M. Pectineus muscle and its nerve-supply. J. Anat. Physiol., 26(Pt. 1):43-7, 1891.

Saha, S. \& Pakhiddey, R. Bilateral high branching pattern of femoral nerve - a clinico-anatomical study. Int. J. Curr. Res. Rev., 5(22):74-7, 2013.

Sharma, M.; Marsolais, E. B.; Polando, G.; Triolo, R. J.; Davis, J. A. Jr.; Bhadra, N. \& Uhlir, J. P. Implantation of a 16-channel functional electrical stimulation walking system. Clin. Orthop. Relat. Res., (347):236-42, 1998.

Sharrock, N. E. Inadvertent "3-in-1 block" following injection of the lateral cutaneous nerve of the thigh. Anesth. Anal., 59(11):887-8, 1980 .

Sim, I. W. \& Webb, T. Anatomy and anaesthesia of the lumbar somatic plexus. Anaesth. Intensive Care, 32(2):178-87, 2004.

Standring, S. Gray's Anatomy. The Anatomical Basis of Clinical Practice. 40th ed. Edinburgh, Churchill Livingstone-Elsevier, 2008. pp.1382-3.

Triolo, R.; Wibowo, M.; Uhlir, J.; Kobetic, R. M. \& Kirsch, R. Effects of stimulated hip extension moment and position on upper-limb support forces during FNS-induced standing--a technical note. J. Rehabil. Res. Dev., 38(5):545-55, 2001.

Tyler, D. J. \& Durand, D. M. Functionally selective peripheral nerve stimulation with a flat interface nerve electrode. IEEE Trans. Neural. Syst. Rehabil. Eng., 10(4):294-303, 2002.
Uhlir, J. P.; Triolo, R. J. \& Kobetic, R. The use of selective electrical stimulation of the quadriceps to improve standing function in paraplegia. IEEE Trans. Rehabil. Eng., 8(4):514-22, 2000.

Uzmansel, D.; Aktekin, M. \& Kara, A. Multiple variations of the nerves arising from the lumbar plexus. Neuroanatomy, 5(1):379, 2006.

Warfel, B. S.; Marini, S. G.; Lachmann, E. A \& Nagler, W. Delayed femoral nerve palsy following femoral vessel catheterization. Arch. Phys. Med. Rehabil., 74 (11):1211-5, 1993.

\author{
Correspondence to: \\ Dr. Rajani Singh Additional Professor \\ Department of Anatomy \\ All India Institute of Medical Sciences \\ Virbhadra Marg \\ Pashulok Rishikesh \\ Dehradun, UK \\ INDIA
}

Email: nani_sahayal@rediffmail.com

Received: 11-02-2016

Accepted: 05-04-2016 